\title{
LIGHT DIFFUSION IN THE TROPICAL DRY FOREST OF COSTA RICA
}

\author{
S. Calvo-Rodriguez ${ }^{\text {a, } * \text {, G.A Sanchez-Azofeifa }}{ }^{\text {a }}$ \\ ${ }^{a}$ Earth and Atmospheric Sciences Department, University of Alberta, Edmonton, AB, Canada, T6G 2E3 - (calvorod, \\ gasanche)@ualberta.ca
}

Commission WG VIII/7

KEY WORDS: Leaf area index, spectral vegetation indices, MODIS

\begin{abstract}
:
Leaf Area Index (LAI) has been defined as the total leaf area (one-sided) in relation to the ground. LAI has an impact on tree growth and recruitment through the interception of light, which in turn affects primary productivity. Even though many instruments exist for estimating LAI from ground, they are often laborious and costly to run continuously. Measurements of LAI from the field using traditional sensors (e.g., LAI-2000) require multiple visits to the field under very specific sky conditions, making them unsuitable to operate in inaccessible areas and forests with dense vegetation, as well as areas where persistent sunny conditions are the norm like tropical dry forests. With this context, we proposed a methodology to characterize light diffusion based on NDVI and LAI measurements taken from the field in two successional stages in the tropical dry forest of Santa Rosa National Park in Costa Rica. We estimate a "K" coefficient to characterize light diffusion by the canopy, based on field NDVI measurements derived from optical phenology instruments and MODIS NDVI. From the coefficients determined, we estimated LAI values and compared them with ground measurements of LAI. In both successional stages ground measurements of LAI had no significant difference to the towerderived LAI and the estimated LAI from MODIS NDVI.
\end{abstract}

\section{INTRODUCTION}

Leaf Area Index (LAI) plays a key role on light interception by the canopy, as the leaf area attenuates and reduces the transmission of radiation to the forest interior. In many forests with closed canopies, only a small fraction $(0.5-5 \%)$ of the solar radiation incident above the canopy reaches the understory (Chazdon and Pearcy, 1991). In Tropical Dry Forests (TDF) around $6-22 \%$ of the solar radiation incident above the canopy reaches the understory (Lebrija-Trejos et al. 2011) because of the low canopy height, simple vertical stratification and low leaf biomass.

TDFs are defined as a vegetation type dominated by deciduous trees (at least $50 \%$ of the trees are deciduous), with an annual average temperature of at least $25^{\circ} \mathrm{C}$ or higher, annual precipitation of 700-2000 $\mathrm{mm}$ per year, and a dry season (precipitation less than $100 \mathrm{~mm}$ ) of three or more months (Sánchez-Azofeifa et al. 2014). In TDFs LAI varies seasonally, having a maximum value during the growing season when water is available and a minimum value at the end of the dry season (Mass et al. 1995; Kalacska et al. 2005). These forests are characterized for a fast increase from $\mathrm{LAI}=0$ in the dry season to full canopy coverage (LAI higher than 7) within a few days after the first rains, and a slow but sustain loss of leaves at the end of the raining season until it reaches again a value of 0 .

Although LAI is important to characterize ecosystem process, availability of LAI data is rare for TDFs (Kalacska et al. 2005). Moreover, a systematic bias exists for LAI observations since most of the data is collected in old growth tropical rain forests without considering differences in canopy structure and composition found in secondary forests or the differences that may exist with other ecosystems (Murphy and Lugo, 1986;
Weaver and Murphy, 1990; Lean and Rowntree, 1993; Kalacska et al. 2005).

Although many instruments exist to characterize LAI from the ground, these methods are often laborious and costly. Unlike most flux sensors that are designed to run in all weather conditions, most ground-based instruments to estimate LAI operate largely under conditions of no precipitation (Wilson and Meyers, 2007) and their observations are punctual in nature since they are related to specific field campaigns when data is collected once without proper temporal follow-up. Measurements of LAI using traditional optical sensors (e.g., LAI-2000) also require multiple visits to the field under very specific sky conditions, making them unsuitable for inaccessible areas and forests with dense vegetation, as well as in areas where persistent sunny conditions are the norm.

Continuous estimations of LAI using remote sensors can be obtained as a function of the spectral Vegetation Indices (VIs), such as the Normalized Differential Vegetation Index (NDVI) (Wilson and Meyers, 2007). NDVI is currently the most widely used reflectance vegetation index (Pontailler et al. 2003). NDVI can be a sensitive indicator of the amount and vigor of the vegetation, because the two wavebands used to estimate it represent the section of the solar spectrum on which the Photosynthetically Active Radiation region takes place (PAR, 400nm to $700 \mathrm{~nm}$ ) (Carlson et al. 1994).

In this context, the main objective of this study was to characterize light diffusion through the canopy in a TDF ecosystem at two different levels of ecological succession by integrating optical phenology observations. A successional stage is defined here as phase on which a given forest is found since its processes of functional recovery started as a community. Depending of their level of succession, a forest

\footnotetext{
* Corresponding author
} 
canopy will have different vertical and horizontal structures, as well as different levels of species, functional traits (Quesada et al. 2009) and light attenuation.

\section{METHODS}

\subsection{Study area}

The study was conducted at the Santa Rosa National Park located in the province of Guanacaste, Costa Rica. The park is located in the tropical dry forest and tropical moist forest according to the classification of Holdridge life zones (Holdridge, 1967). The area under study is specifically deployed in the early stage and intermediate stage of succession of TDF, having a bio-temperature not less than $24^{\circ} \mathrm{C}$ and annual precipitation average between 1,500 and 2,200 mm (Hartshorn, 1983). Rain falls primarily between early April and early November, and the rest of the year is nearly without rain (Janzen, 1993). The present study was carried in two phases, from March 2010 to March 2011 field measurements were taken in the early stage of succession. From March 2013 to March 2015 field measurements were taken in the intermediate stage of succession.

\subsection{Experimental Design}

The first component of this research involved the deployment of two optical phenology towers. The optical phenology towers are structures with a set of radiation sensors. Two-pyranometers (measuring the solar radiation flux density) and two photosynthetic active radiation sensors (measuring the radiation only between 400 and $700 \mathrm{~nm}$ ). Ratios of these measurements were used to derive vegetation indexes such as the NDVI. In the intermediate stage of succession one $20 \mathrm{~m}$ height tower was deployed in 2013 and in the early stage one $15 \mathrm{~m}$ height tower was deployed in 2009. In both cases sensors are at least 5 meters above the canopy (Pastorello et al. 2011).

For the determination of the LAI, around each optical phenology tower 3 plots were established. The early plots contain 165 points in total for measuring LAI and the intermediate plots contain 84 points in total. The measurements were collected every month, using a Plant Canopy Analyzer (PCA) LAI-2000 which gives a measurement of the Plant Area Index (PAI) of each point. In the dry season, hemispherical photographs in each sampling point were taken, using a camera with a $180^{\circ}$ lens (fish-eye) to calculate the Woody Area Index (WAI) (Sanchez-Azofeifa et al. 2009). Finally, we calculated the specific Leaf Area Index (LAI) by removing the contribution of WAI from PAI values (Kalacska et al. 2005).

Further information about the study site, deployment of plots and LAI data and the optical phenology towers can be found in (Calvo-Rodriguez, 2015).

\subsection{Data analysis}

Using the information collected by the optical phenology towers in the plots, we calculate the Normalized Difference Vegetation Index (NDVI) for each successional stage using the formulas described in Wilson and Meyers (2007). For this study only the measurements obtained between 10:00 and 14:00 hours were considered, to avoid inference of bidirectional reflectance (Disney, 2004). In addition, we obtained NDVI data derived from MODIS/TERRA (product MOD13Q1, collection 5, 16day L3 Global $250 \mathrm{~m}$ ) for all the plots where LAI was measured (ORNL DAAC, 2012).

To calculate "K" we used the NDVI data and the LAI data to solve equation (1) given by (Campbell and Norman, 1998; Wilson and Meyers, 2007)

$$
\text { LAI }=- \text { Klog } \frac{\text { NDVImax-NDVli }}{\text { NDVImax }- \text { NDVImin }}
$$

Where $\mathrm{NDVI}_{\max }$ corresponds to the average of NDVI values when the vegetation is dense (peak of rainy season); $\mathrm{NDVI}_{\min }$ is the average of NDVI measured during the dry seasons, with leaf off; and $\mathrm{NDVI}_{\mathrm{i}}$ is the mean of all changes in NDVI values during the rainy season. The LAI value is determined by the average of all the sampling points in each plot.

To compare the potential of NDVI to estimate the "K" coefficient, we correlate NDVI with LAI. Coefficients of determination $\left(\mathrm{R}^{2}\right)$ were used to assess their performance. After this, we proceeded to calculate the "K" coefficient from equation 1, using the NDVI data derived from the phenology towers and MODIS satellite and the LAI data derived from the plots.

The "K" values were obtained for different days of the year (DOY) for each successional stage. Nonlinear regression analysis was used to assess the variation of the "K" coefficient throughout the year. Using the models derived from the regression curve, we estimated the LAI using only the "K" values and the NDVI derived from the optical phenology towers, and the MODIS data. To evaluate the estimation capability of the models, we examined the relationship between the observed LAI data using the LAI-2000, against the estimated data of LAI using the "K" coefficients derived from the phenology towers, and from MODIS NDVI using least squares linear regression. The performance of the models was evaluated using the coefficient of determination $\left(R^{2}\right)$, and the Root Mean Squared Error (RMSE). The higher the $\mathrm{R}^{2}$ and the lower the RMSE, the better the accuracy of the model to estimate LAI.

\section{RESULTS AND DISCUSSION}

The NDVI was correlated with LAI values in each successional stage using data from MODIS and the Optical Phenology Tower observations. The correlation with LAI (Figure 1) in the early successional stage was NDVI $\left(\mathrm{R}^{2}=0.85\right)$ for the tower-based data and NDVI $\left(\mathrm{R}^{2}=0.87\right)$ for MODIS satellite data. In the intermediate successional stage, the correlation with LAI was NDVI $\left(\mathrm{R}^{2}=0.87\right)$ for the tower-based data followed by MODIS NDVI $\left(\mathrm{R}^{2}=0.73\right)$ for satellite data. 

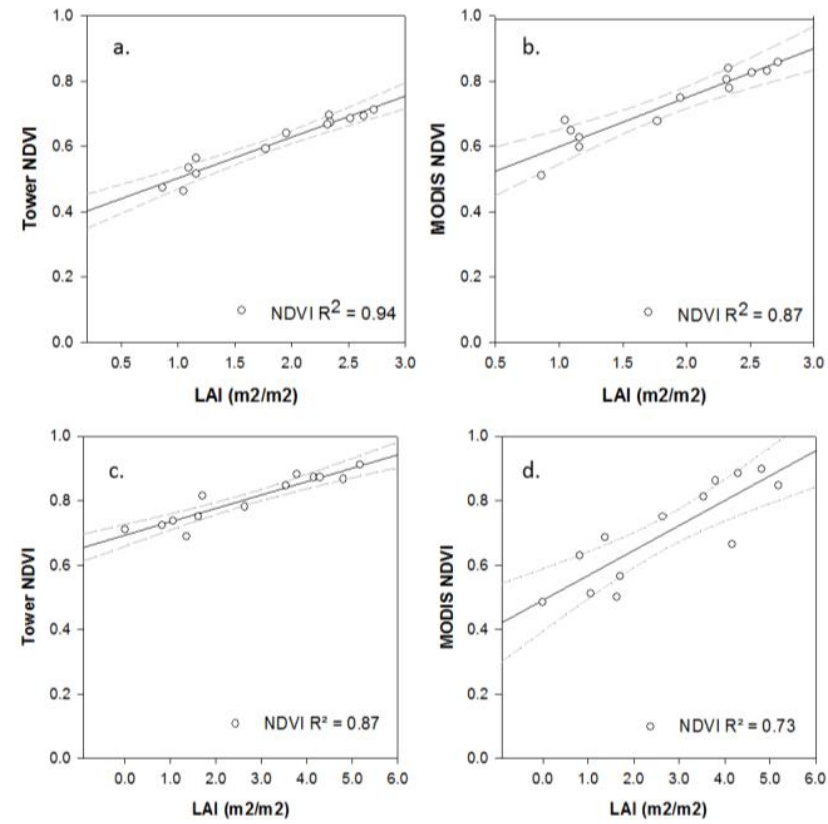

Figure 1. Correlations between LAI and NDVI in early (a. and b.) and intermediate successional plots (c. and d.) in the Santa Rosa National Park, Guanacaste. Dashed lines represent the $99 \%$ confidence intervals.

As expected, values of " $\mathrm{K}$ " were higher in the intermediate successional stage, lower in the early successional stage, and varied as a function of time (Figure 2). Maximum values occurred in the month of September, in both successional stages and minimum values occurred during the dry season (JanuaryApril).
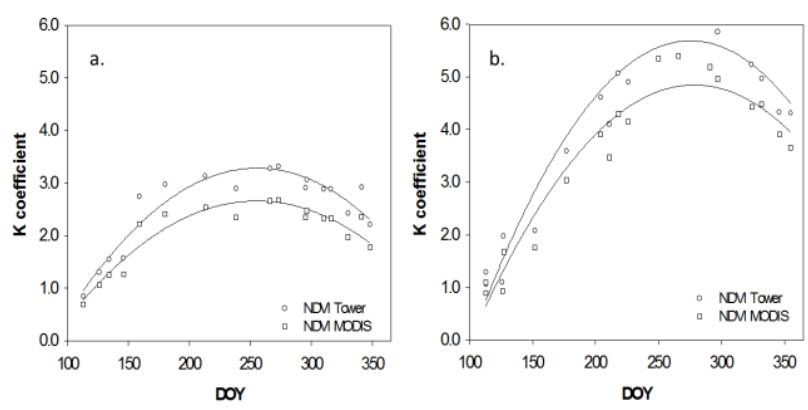

Figure 2. Variation of " $\mathrm{K}$ " coefficient during the days of the year (DOY). Early successional plots (a.) and intermediate successional plots (b.) for Santa Rosa National Park, Guanacaste.

Table 1 presents results from the estimation of the " $K "$ coefficient using equation 1 . The average " $K$ " coefficient for the growing season (End of May-beginning of December) was higher than 4 in the intermediate stage of succession and lower than 3 in the early stage of succession. Although "K" values using MODIS NDVI tended to be lower, there was no significant difference between the vegetation index (MODIS NDVI or Tower NDVI) used to estimate the "K" coefficient in the early stage $(\mathrm{p}=0.073)$ or in the intermediate stage $(\mathrm{p}=0.416)$.
Table 1. The maximum, minimum, and seasonal changes $\left(\mathrm{NDVI}_{\max }, \mathrm{NDVI}_{\min }\right.$ and $\mathrm{NDVI}_{\mathrm{i}}$ ) used to find the "K" coefficient in the early and intermediate successional plots and the maximum and average " $\mathrm{K}$ " values found for the growing season in Santa Rosa National Park, Guanacaste.

\begin{tabular}{ccccccc}
\hline Succession & NDVI & $\begin{array}{c}\text { NDVI } \\
\text { min }\end{array}$ & $\begin{array}{c}\text { NDVI } \\
\text { max }\end{array}$ & NDVI $_{\mathbf{i}}$ & $\begin{array}{c}\mathbf{K} \\
\mathbf{m a x}\end{array}$ & $\overline{\mathbf{K}}$ \\
\hline Early Stage & Tower & 0.52 & 0.69 & 0.66 & 3.28 & 2.84 \\
& MODIS & 0.54 & 0.79 & 0.77 & 2.90 & 2.51 \\
Intermediate & Tower & 0.72 & 0.89 & 0.86 & 6.31 & 4.89 \\
Stage & MODIS & 0.57 & 0.84 & 0.81 & 5.70 & 4.41 \\
\hline
\end{tabular}

Variations can be explained by the lower values of NDVI found in MODIS data. Differences between NDVI values measured from the ground, and determined from satellites have been reported in the literature (Wang et al. 2004; Jenkins et al. 2007; Wilson and Meyers, 2007). Main variations in satellite NDVI data are due to atmospheric effects, strong effects of temporal sampling, remaining cloud cover, seasonality of vegetation and data processing (Wang et al. 2004). Also Hmimina et al. (2012) emphasize that ground-based NDVI measurements are acquired at constant viewing angles, while MODIS satellite measurements are acquired with different viewing geometries. Moreover, any comparison with spectral-based NDVI must recognize that the wavelength used for the satellite-derived NDVI $\left(\mathrm{R}_{\text {red }}: 610 \mathrm{~nm}-680 \mathrm{~nm}\right.$, and $\left.\mathrm{R}_{\text {nir }}: 820 \mathrm{~nm}-900 \mathrm{~nm}\right)$ are quite different from those used in broadband NDVI calculations $\left(\mathrm{R}_{\text {red }}\right.$ : 400-700nm, $\mathrm{R}_{\text {nir }}$ : 305-2800nm) (Tittebrand et al. 2009). All the mentioned above might cause discrepancies in " $K$ " values derived from ground measurements or satellite data.
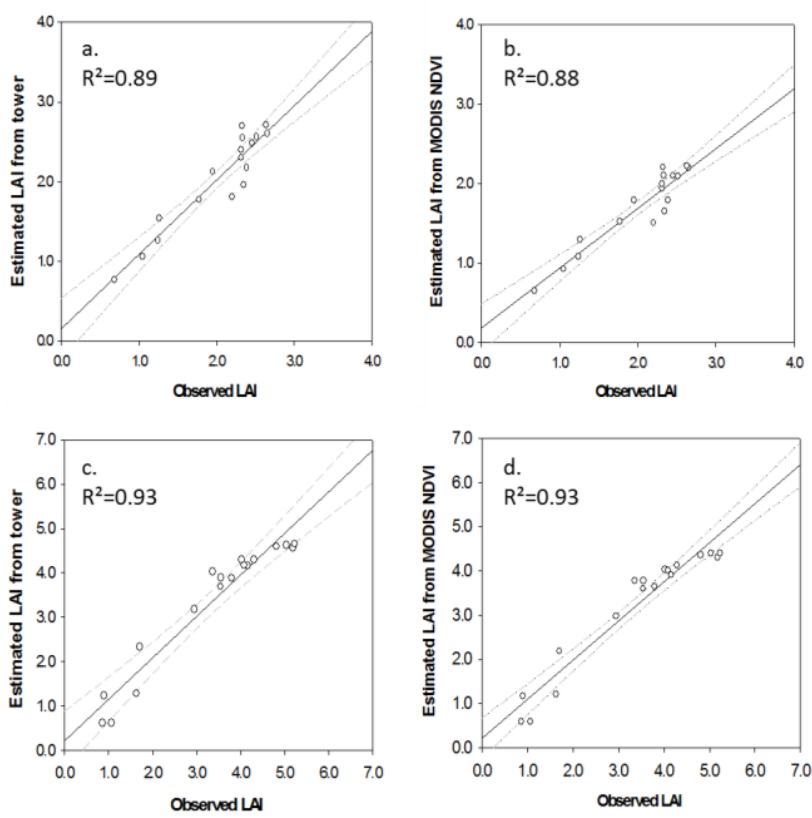

Figure 3. Correlations between estimated LAI and observed LAI for the early successional plots (a. and b.) and the intermediate successional plots (c. and d.) in the Santa Rosa National Park, Guanacaste. Dashed lines represent the 99\% confidence intervals.

The strength of the relationship of the observed LAI (LAI-2000) and the estimated LAI derived from tower data (Figure 3) was strong in the early successional stage and in the intermediate 
successional stage $\left(\mathrm{R}^{2}=0.89\right.$ and $\mathrm{R}^{2}=0.93$ respectively). This relationship was also strong for the observed LAI (LAI-2000) and the estimated LAI derived from MODIS NDVI in the early successional stage and in the intermediate successional stage $\left(\mathrm{R}^{2}=0.88\right.$ and $\mathrm{R}^{2}=0.93$ respectively).

For both successional stages, RMSE (Table 2) were also lower using the phenology tower data (RMSE $=0.20$ in the early stage, and $\mathrm{RMSE}=0.37$ in the intermediate stage).

Table 2. Evaluation of the different methods to derive LAI in Santa Rosa National Park, Guanacaste.

\begin{tabular}{cccc}
\hline Stage & Method & Model to determine "K" & RMSE \\
\hline \multirow{3}{*}{ Early } & $\begin{array}{c}\text { Tower } \\
\text { NDVI } \\
\text { MODIS } \\
\text { NDVI }\end{array}$ & $4.2+0.059(\mathrm{DOY})-1.15 \mathrm{E}-4\left(\mathrm{DOY}^{2}\right)$ & 0.20 \\
\hline \multirow{3}{*}{ Intermediate } & $\begin{array}{c}\text { Tower } \\
\text { NDVI }\end{array}$ & $-8.50+0.103(\mathrm{DOY})-1.87 \mathrm{E}-4\left(\mathrm{DOY}^{2}\right)$ & 0.37 \\
& $\begin{array}{c}\text { MODIS } \\
\text { NDVI }\end{array}$ & $-7.05+0.085(\mathrm{DOY})-1.54 \mathrm{E}-6\left(\mathrm{DOY}^{2}\right)$ & 0.42 \\
\hline
\end{tabular}

Numerous studies have reported a good relationship between the MODIS NDVI and ground measurements of phenological parameters (Wang et al. 2005; Fontana et al. 2008; Eklundh et al. 2011). Values of NDVI can differ between similar sites, depending on local environmental factors like understory vegetation, litter, soil surface conditions, humidity, and roughness (Lacaze et al. 1996). Overall, values of "K" obtained from the NDVI of the optical phenology towers seemed to be more accurate for the estimation of LAI. According to Wilson and Meyers (2007), tower-derived NDVI is less affected by cloudy conditions, because continuous 30 -min measurements of incoming solar radiation at the flux towers allows the investigator to directly identify and remove cloudy data points and outliers for the derivation of NDVI.

Moreover, the treatment of the "K" coefficient and LAI as variables rather than constants over time is an improvement to reduce serious deviations in the LAI estimation in TDFs and, thereby, in estimates of carbon balances and primary productivity. In most studies in temperate environments only a single dataset is used to establish the (LAI, NDVI) relationship. These temperate ecosystems relationships also do not take into consideration the seasonal or year-to-year dynamics of deciduous ecosystems, which are fundamentally important to estimate the temporal variability of LAI (Wang et al. 2005).

\section{CONCLUSIONS}

Strong correlation between NDVI and LAI demonstrates that it is possible to obtain accurate LAI values based on spectral features of vegetation derived from phenology towers or satellite data. Furthermore, the "K" coefficients differed between successional stages, indicating sensitivity to structural changes during forest restoration. Once this " $\mathrm{K}$ " coefficient is validated, it could be used to obtain accurate and automated LAI values for larger areas in TDF. This research provides information for validating satellite products and calibrating new algorithms for such products.

\section{ACKNOWLEDGEMENTS}

This work is part of the Research Project TROPI-DRY (Human, Ecological and Biophysical Dimension on Tropical Dry Forest), which is a collaborative research network funded by the Inter American Institute for Global Change Research (IAI) Collaborative Research Network Program (CRN3-025). We acknowledge logistical support by the University of Alberta and the Costa Rica Institute of Technology (ITCR).

\section{REFERENCES}

Calvo-Rodriguez, S. 2015. Ecosystem Services, Forest Characterization, and Light Diffusion of Tropical Dry Forests. (dissertation). University of Alberta, Edmonton, Canada.

Campbell, G., Norman, J., 1998. An Introduction to Environmental Biophysics. Springer-Verlag, New York, pp. 247-260.

Carlson, T. N., Gillies, R. R., Perry, E. M., 1994. A method to make use of thermal infrared temperature and NDVI measurements to infer surface soil water content and fractional vegetation cover. Remote Sensing Reviews, 9, pp. 161-173.

Chazdon, R.L., Pearcy, R.W., 1991. The Importance of Sunflecks for Forest Understory Plants. BioScience, 41(11), pp. 760-766.

Disney, M., Lewis, P., Thackrah, G., Quaife, T., Barnsley, M., 2004. Comparison of MODIS broadband albedo over an agricultural site with ground measurements and values derived from earth observation data at a range of spatial scales. International Journal of Remote Sensing, 25(23), pp. 52975317.

Eklundh, L., Jin, H., Schubert, P., Guzinski, R., Heliasz, M., 2011. An optical sensor network for vegetation phenology monitoring and satellite data calibration. Sensors, 11, pp. 76787709.

Fontana, F., Rixen, C., Jonas, T., Aberegg, G., Wunderle, S., 2008. Alpine grassland phenology as seen in AVHRR, VEGETATION, and MODIS NDVI time series a comparison with in situ measurements. Sensors, 8(4), pp. 2833-2853.

Hartshorn, G.S., 1983. Chapter 7: Plants. In D.H. Janzen (Ed.): Costa Rican Natural History, University of Costa Rica: San Jose, C.R, pp. 118-157.

Hmimina, G., Dufrêne, E., Pontailler, J. Y., Delpierre, N., Aubinet, M., Caquet, B., de Grandcourt, A., Burban, B., Flechard, C., Granier, A., Gross, P., Heinesch, B., Longdoz, B., Moureaux, C., Ourcival, J.M., Rambal, S., Saint André, L., Soudani, K., 2013. Evaluation of the potential of MODIS satellite data to predict vegetation phenology in different biomes: An investigation using ground-based NDVI measurements. Remote Sensing of Environment, 132, pp. 145158.

Holdridge, L.R., 1967. Life zone ecology. Tropical Science Center, San Jose, CR, pp. 40-43. 
Janzen, D.H., 1993. Caterpillar seasonality in a Costa Rican dry forest. In N.E. Stamp and T.M. Casey (Eds.): Caterpillars: Ecological and evolutionary constraints on foraging, Chapman \& Hall, London, pp. 448-477.

Jenkins, J.P., Richardson, A.D., Braswell, B.H., Ollinger, S.V., Hollinger, D.Y., Smith, M.L., 2007. Refining light-use efficiency calculations for a deciduous forest canopy using simultaneous tower-based carbon flux and radiometric measurements. Agricultural and Forest Meteorology, 143, pp. 64-79.

Kalacska, M.E.R., Calvo-Alvarado, J.C., Sánchez-Azofeifa, G.A., 2005. Calibration and assessment of seasonal changes in species leaf area in a tropical dry forest in different states of succession. Tree Physiology, 25, pp. 733-744.

Kalacska, M.E.R., Sanchez-Azofeifa, G.A., Calvo-Alvarado, J.C., Rivard, B., Quesada, M., 2005. Effects of season and successional stage on leaf area index and spectral vegetation indices in three Mesoamerican tropical dry forests. Biotropica, 37, pp. 486-496.

Lacaze, B., Caselles, V., Coll, C., Hill, J., Hoff, C., Jong, S. De, Valor, E., 1996. Integrated Approaches To Desertification Mapping and Monitoring in the Mediterranean Basin. Final report of the DeMon-1 Project, Space Applications Inst., Environmental Mapping and Modelling Unit, Brussels, 165 pp.

Lean, J., Rowntree, P. R. 1993., GCM simulation of the impact of Amazonian deforestation on climate using an improved canopy representation. Quarterly Journal of the Royal Meteorological Society, 119, pp. 509-530.

Lebrija-Trejos, E., Pérez-García, E.A., Meave, J.A., Poorter, L., Bongers, F., 2011., Environmental changes during secondary succession in a tropical dry forest in Mexico. Journal of Tropical Ecology, 27, pp. 477-489.

Murphy, P.G., Lugo, A.E., 1986. Ecology of tropical dry forests. Annals Review of Ecology and Systematics, 17, pp. 6788 .

Oak Ridge National Laboratory Distributed Active Archive Center (ORNL DAAC). 2012. MODIS subsetted land products, $\begin{array}{llll}\text { Collection } & 5 . & \text { Retrieved }\end{array}$ [http://daac.ornl.gov/MODIS/modis.html]

Pastorello, G.Z., Sánchez-Azofeifa, G.A., Nascimento, M.A., 2011. Enviro-Net: From Networks of Ground-Based Sensor Systems to a Web Platform for Sensor Data Management. Sensors, 11(6), pp. 6454-6479.

Pontailler, J.Y., Hymus, G. J., Drake, B.G., 2003. Estimation of leaf area index using ground-based remote sensed NDVI measurements: validation and comparison with two indirect techniques. Canadian Journal of Remote Sensing, 29(3), pp. 381-387.

Quesada, M., Sánchez-Azofeifa, G.A., Alvarez-Anorve, M., Stoner, K.E., Avila-Cabadilla, L., Calvo-Alvarado, J.C., Castillo, A., do Espirito-Santo, M. M., Fagundes, M., Fernandes, G. W., Gamon, J., Lopezaraiza-Mikel, M., Lawrence, D., Morellato, L.P.C., Powers, J.S., Neves, F.S.,
Rosas-Guerrero, V., Sayago, R., Sánchez-Montoya, G., 2009. Succession and management of tropical dry forests in the Americas: Review and new perspectives. Forest Ecology and Management, 258, pp. 1014-1024.

Sánchez-Azofeifa, G.A., Calvo-Alvarado, J.C., do EspíritoSanto, M.M., Fernandes, G.W., Powers, J., Quesada, M., 2014. Tropical Dry Forests in the Americas: The Tropi-Dry Endeavor. In: Sánchez-Azofeifa, G.A. and Powers, J. (Eds.): Tropical Dry Forests in the Americas: Ecology, Conservation, and Management, CRC Press, Boca Raton, FL, pp 1-16.

Sánchez-Azofeifa, G.A., Kalacska, M., do Espirito-Santo, M. M., Fernandes, G. W., Schnitzer, S., 2009. Tropical dry forest succession and the contribution of lianas to wood area index (WAI). Forest Ecology and Management, 258(6), pp. 941-948.

Tittebrand, A., Spank, U., Bernhofer, C.H., 2009. Comparison of satellite-and ground-based NDVI above different land-use types. Theoretical and applied climatology, 98(1-2), pp. 171186.

Wang, Q., Adiku, S., Tenhunen, J., Granier, A., 2005. On the relationship of NDVI with leaf area index in a deciduous forest site. Remote Sensing of Environment, 94(2), pp. 244-255.

Wang, Q., Tenhunen, J., Dinh, N.Q., Reichstein, M., Vesala, T., Keronen, P., 2004. Similarities in ground-and satellite-based NDVI time series and their relationship to physiological activity of a Scots pine forest in Finland. Remote Sensing of Environment, 93(1), pp. 225-237.

Weaver, P. L., Murphy, P. G., 1990. Forest structure and productivity in Puerto Rico's Luquillo Mountains. Biotropica, 22, pp. 69-82.

Wilson, T.B., Meyers, T.P., 2007. Determining vegetation indices from solar and photosynthetically active radiation fluxes. Agricultural and Forest Meteorology, 144, pp. 160-179. 